\title{
DISCUSSION
}

\section{Compressibility behaviour of soft cemented soils}

\author{
T. S. NAGARAJ, N. S. PANDIAN and P. S. R. NARASIMHA RAJU (1998). Géotechnique 48, No. 2, $281-287$.
}

\section{S. J. Boone, Golder Associates Ltd, Canada}

In the paper, it is suggested that a soil's physical state can be deduced by dividing the in situ voids ratio $\left(e_{0}\right)$ by the voids ratio at the liquid limit water content $\left(e_{\mathrm{L}}\right)$ and comparing this ratio to equation (1) (see Fig. 8). Equation (1) implies that,

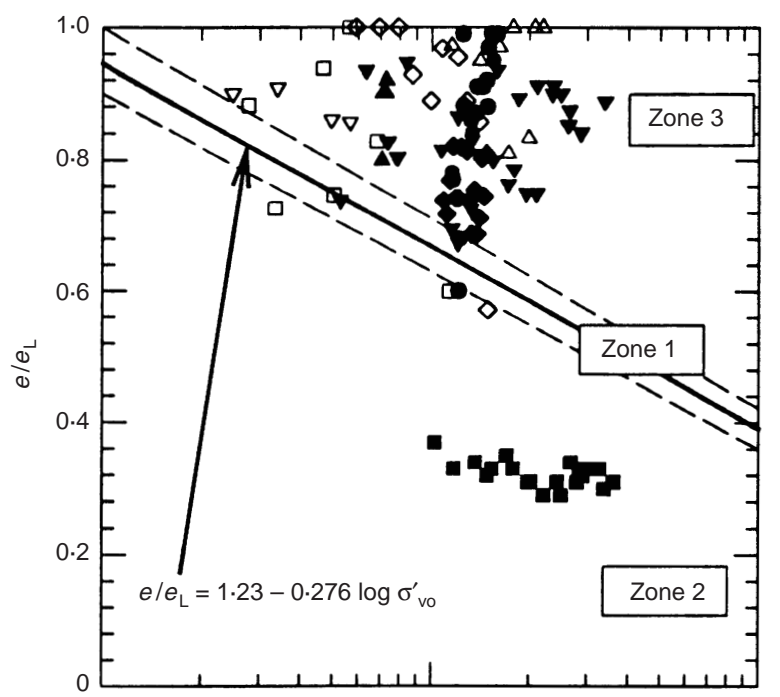

(a)

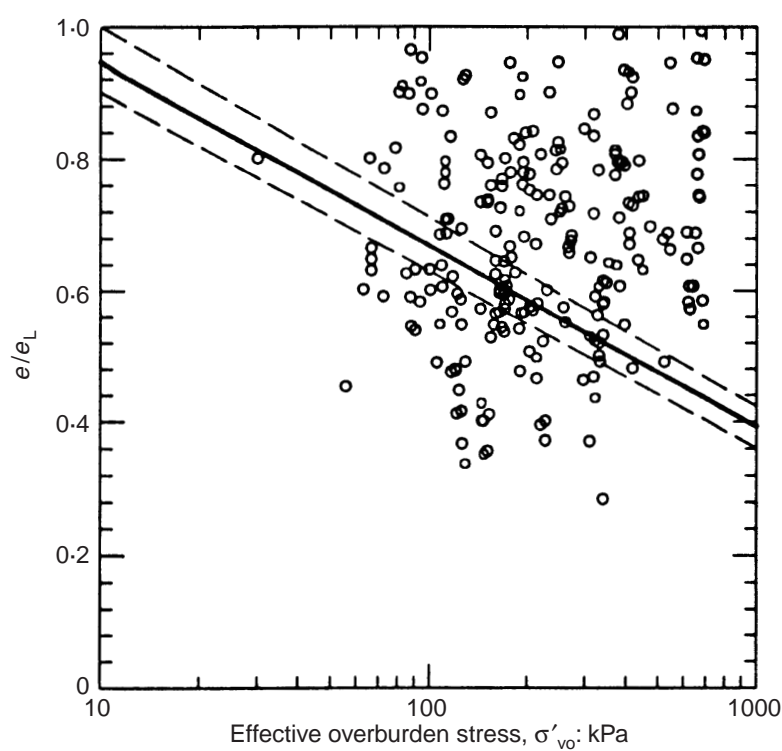

(b)

$\begin{array}{lll}\text { - NY Varved Clays } & \boldsymbol{0} & \text { Toronto } \\ \text { - London Clay } & \boldsymbol{口} & \text { Leda Clay, Ottawa, Canada } \\ \boldsymbol{\Delta} \text { Mexico City } & \Delta & \text { Drammen } \\ \text { - Chicago } & \boldsymbol{\Delta} & \text { New Liskeard, Canada } \\ \boldsymbol{\nabla} \text { Boston Blue Clay } & \boldsymbol{\nabla} & \text { Singapore }\end{array}$

Fig. 8. Comparison of various soil deposits to equation (1). Zone 1, normally consolidated, uncemented. Zone 2 , overconsolidated, uncemented. Zone 3, naturally cemented. Zones shown based on Nagaraj \& Srinivasa-Murthy (1983). See Boone \& Lutenegger (1997) for data sources without cementation, the voids ratio (e) should decrease with increasing stress along a unique line derived from soils remoulded at their liquid limit. The principles illustrated in Fig. 8 , while attractive for their simplicity, neglect the fact that the physical state of the soil in situ will be influenced by many factors, including: sedimentation and cementation rate; mineralogy; pore water chemistry; and other weathering or leaching effects. It is possible that a soil could be cemented following sedimentation. Saline flocculation during deposition can have a pronounced effect on the physical state of a soil, depending on its mineralogy. Therefore, the $e_{0} / e_{\mathrm{L}}$ of a particular soil could place it in any of the zones shown in Fig. 8 without being truly reflective of its degree of cementation or compression behaviour.

The authors have concluded that cementation bond strength remains constant or increases during compression beyond the vertical effective yield stress ('preconsolidation pressure') and that equation (1) represents all non-cementation-related compression characteristics of soils (Nagaraj \& Srinivasa-Murthy, 1983, 1986; Nagaraj et al., 1990; Vatsala et al., 1995). Considering, then, that $e_{0}$ represents the 'overall physico-chemical potential of the soil', $e_{0}$ is substituted for $e_{\mathrm{L}}$ in equation (1) as equation (8). The method used to predict a consolidation curve adds the yield stress $\left(\sigma_{\mathrm{vy}}^{\prime}\right)$ to equation (8). A generalized equation is also provided relating $\sigma_{\mathrm{vy}}^{\prime}$ to the undrained shear strength $\left(S_{\mathrm{u}}\right)$ for 'many Canadian soft soils', and it is suggested that consolidation curves can be derived using this correlation, equation (8), and measurements of only $S_{\mathrm{u}}$ and $e_{0}$.

Figure 9 and Table 1 provide data for cohesive soils of varying strength from New York State, Toronto (Ontario), and Mattagami (Quebec), and one of Leda clay from Breckenridge (Quebec). All but one of the curves exhibit $e / e_{\mathrm{L}}$ positions above the equation (1) line and would therefore be classified as 'cemented'. The till sample, not surprisingly, would be considered to be overconsolidated. Based on the mineralogy and behaviour of the soils, the discusser and others consider these soils to be cemented to varying degrees (e.g. Sangrey, 1972;

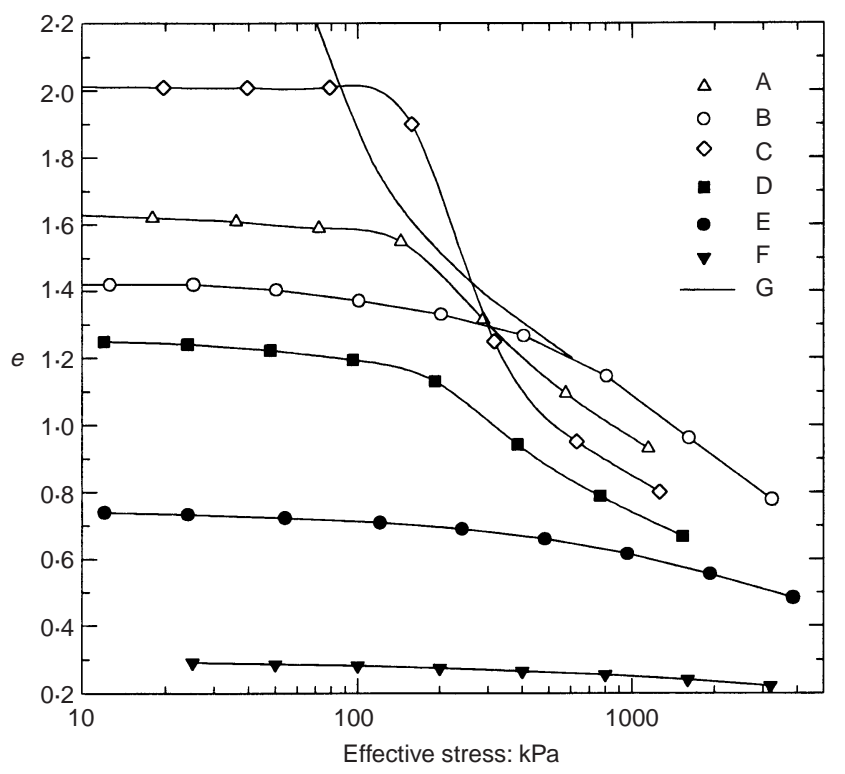

Fig. 9. Example oedometer test curves for naturally cemented soils 
Table 1. Summary of geotechnical parameters for compression curves illustrated in Figs 9-13

\begin{tabular}{|c|c|c|c|c|c|c|c|}
\hline \multirow[t]{2}{*}{ Parameter } & \multicolumn{7}{|c|}{ Curve } \\
\hline & A & B & $\mathrm{C}^{\mathrm{a}}$ & $\mathrm{D}$ & $\mathrm{E}$ & $\mathrm{F}$ & $\mathrm{G}^{\mathrm{b}}$ \\
\hline $\begin{array}{l}\text { Natural water content, } w_{\mathrm{n}}: \% \\
\text { Liquid limit water content, } w_{\mathrm{L}}: \% \\
\text { Liquidity index } \\
\text { Undrained shear strength, } S_{\mathrm{u}}: \mathrm{kPa} \\
\text { In situ vertical effective stress, } \sigma_{\mathrm{vo}}^{\prime} \\
\text { Vertical effective yield stress, } \sigma_{\mathrm{vy}}^{\prime} \\
e_{0} / e_{\mathrm{L}} \\
\left(e_{0} / e_{\mathrm{L}}\right) /(\text { equation } 1 \text { value) } \\
\text { Sensitivity } \\
\text { Origin }\end{array}$ & $\begin{array}{c}60 \\
64 \\
0 \cdot 88 \\
\approx 40 \\
68 \\
145 \\
0 \cdot 93 \\
1 \cdot 28 \\
50 \\
\mathrm{GL} / \mathrm{GM}\end{array}$ & $\begin{array}{l}52 \\
54 \\
1 \cdot 08 \\
\approx 75-100 \\
110 \\
460 \\
0 \cdot 96 \\
1 \cdot 44 \\
10 \\
\text { GL }\end{array}$ & $\begin{array}{l}80 \\
70 \\
1 \cdot 24 \\
\approx 60 \\
130 \\
150 \\
1 \cdot 14 \\
1 \cdot 76 \\
100 \\
\text { GM }\end{array}$ & $\begin{array}{l}45 \\
54 \\
0 \cdot 59 \\
\approx 40 \\
116 \\
180 \\
0 \cdot 83 \\
1 \cdot 26 \\
2-10 \\
\text { GL }\end{array}$ & $\begin{array}{rl} & 26 \\
& 31 \\
0 \cdot 50 & \\
\approx & 100 \\
167 \\
> & 700 \\
& 0 \cdot 84 \\
1 \cdot 36 & \\
2-10 & \mathrm{GL}\end{array}$ & $\begin{array}{c}9 \cdot 5 \\
18 \\
-0 \cdot 60 \\
\approx 575 \\
197 \\
\text { NA } \\
0 \cdot 52 \\
0 \cdot 87 \\
\text { NA } \\
\text { TILL }\end{array}$ & $\begin{array}{c}104 \\
63 \cdot 5 \\
2 \cdot 16 \\
\mathrm{NA} \\
30 \cdot 5 \\
57 \\
1 \cdot 63 \\
1 \cdot 99 \\
\approx 80^{\mathrm{c}} \\
\text { GL }\end{array}$ \\
\hline
\end{tabular}

${ }^{a}$ From Masterson (1970); ${ }^{b}$ from Dascal \& Laroque (1973); ${ }^{c}$ sensitivity based on reported value from Sangrey (1972). GL, glacio-lacustrine; GM, glacio-marine; TILL, glacial till.

Boone \& Lutenegger, 1997). All samples were considered to be good quality samples with little disturbance.

Figure 10 compares the consolidation curves of Fig. 9 to equation (8). The differences between the equation (8) line and the corresponding stresses on the consolidation curves $\left(\sigma_{\mathrm{c}}^{\prime}\right)$ are not consistently equal to the yield stress for any of these soils, as illustrated by Fig. 11. Similar inconsistencies have been identified for soils from the southern Ontario region when using similar approaches (Vatsala et al., 1995; and Joshi et al., 1995). Curve $\mathrm{G}$, also considered to be a soft cemented clay, drops below the line defined by equation (8). It is not considered that Figs 10 and Fig. 11 illustrate any increase in 'bonding' stress because of the departure from equation (8). Rather, these test results simply show increased resistance to compression at high stresses, probably due to the combined effects of remaining cemented bonds as well as progressively more limited opportunity for particle rearrangement without particle crushing.

The shape of the authors' oedometer test curves has been implied to be a unique characteristic of a cemented soil. Depending on the factors discussed above, however, a soil could exhibit a smoother compression curve (e.g. Griffiths \& Joshi, 1988; Becker et al., 1987; Boone \& Lutenegger, 1997). The observed shape of the authors' compression curves and variations in sensitivity for some soft clays of eastern Canada probably arise from saline flocculation during deposition and subsequent leaching, as well as cementation (Quigley, 1980; Boone \& Lutenegger, 1997).

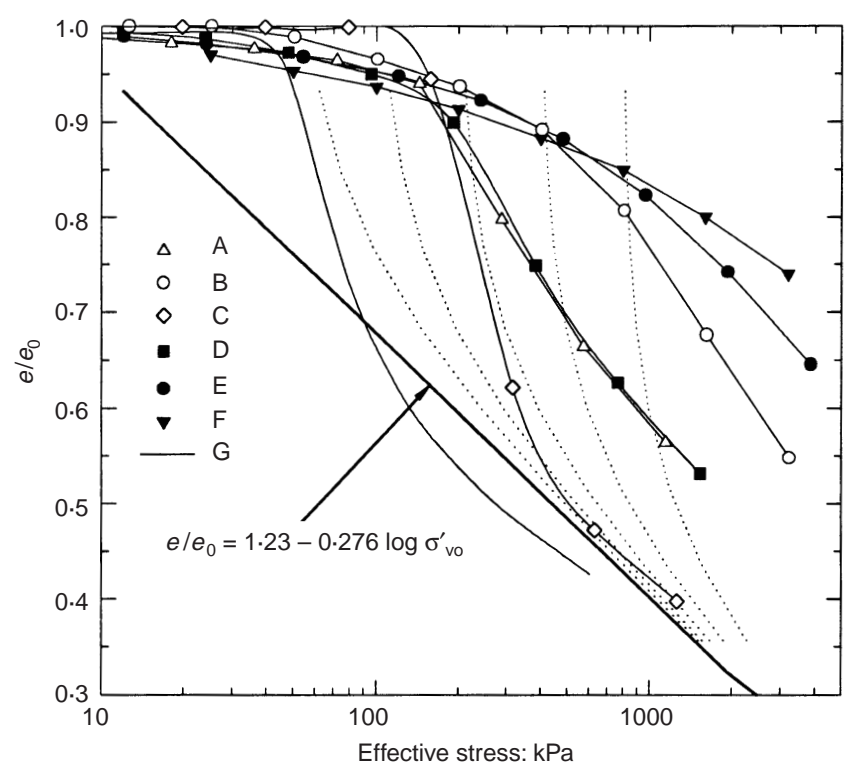

Fig. 10. Comparison of oedometer test curves from Fig. 9 and equation (1) with $e_{0}$ substitution as the authors propose. Dotted lines illustrate the contours of bond stress of 50, 100, 200, 400 and $800 \mathrm{kPa}$

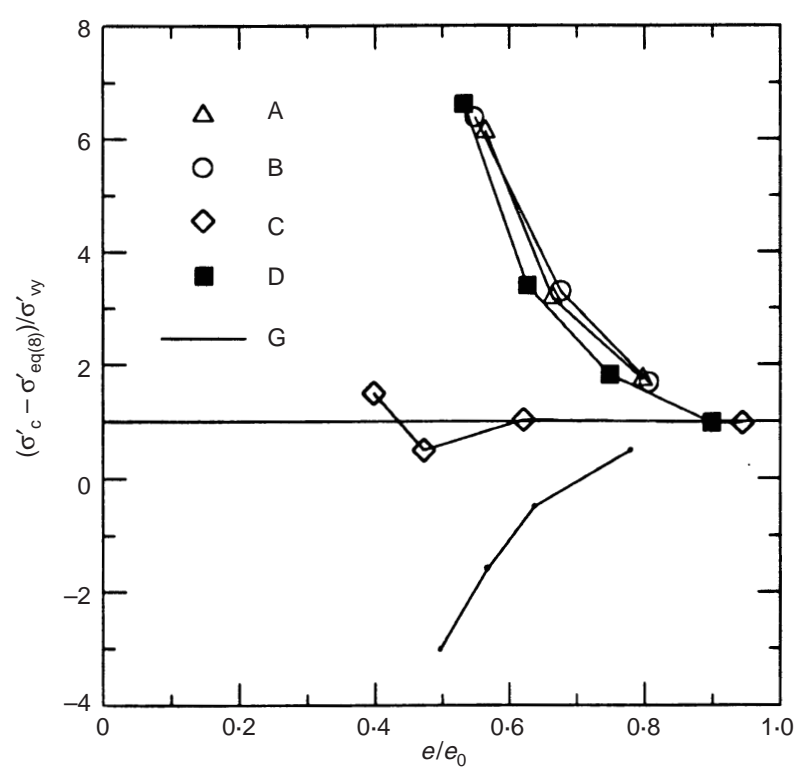

Fig. 11. Comparison of stresses derived from equation (1), yield stresses, and stress points from consolidation test results

Until a better understanding of the factors involved in cementation is achieved, compression curves may be best understood in terms of conventional empirical relations. Intuitively, correlations of compressibility to $e_{0}$ or $w_{\mathrm{n}}$ are rational, since they should indicate the void space available to accommodate compression. This principle is reflected in many published compression index $\left(C_{\mathrm{c}}\right)$ correlations (e.g. summary by Kulhawy \& Mayne (1990). If $\sigma_{\mathrm{vy}}^{\prime}$ and $e_{0}$ can be determined and used as a starting point, a consolidation curve can be reconstructed using simple $w_{\mathrm{n}}$ and $C_{\mathrm{c}}$ relationships. By using small incremental increases in load, successive $e$ and $C_{\mathrm{c}}$ values can be calculated to construct the curve beyond $\sigma_{\mathrm{vy}}^{\prime}$ (Fig. 12). If a reasonable correlation existed between $S_{\mathrm{u}}$ and $\sigma_{\mathrm{vy}}^{\prime}$ for this deposit, future projects may not require many oedometer tests to determine compression curves, provided that $S_{\mathrm{u}}$ and $e_{0}$ were determined. This approach, while similar to the authors', does not require fundamental assumptions about the differences between equation (8) and observed test curves, but uses local data directly. Fig. 13 illustrates this approach using data from Toronto's glacio-lacustrine clays. Although perfect curve matches are not achieved for an individual test, the locally derived correlations provide rational and statistical bases on which to judge the likely compressibility behaviour of the soil mass.

Compression characteristics of a soil are defined by many factors that remain outside the scope of the paper and equations (1) and (8). It may be that physical state lines similar to that defined by equations (1) or (8) exist for other soils and pore water chemistries. Equations (1) and (8), however, should not 


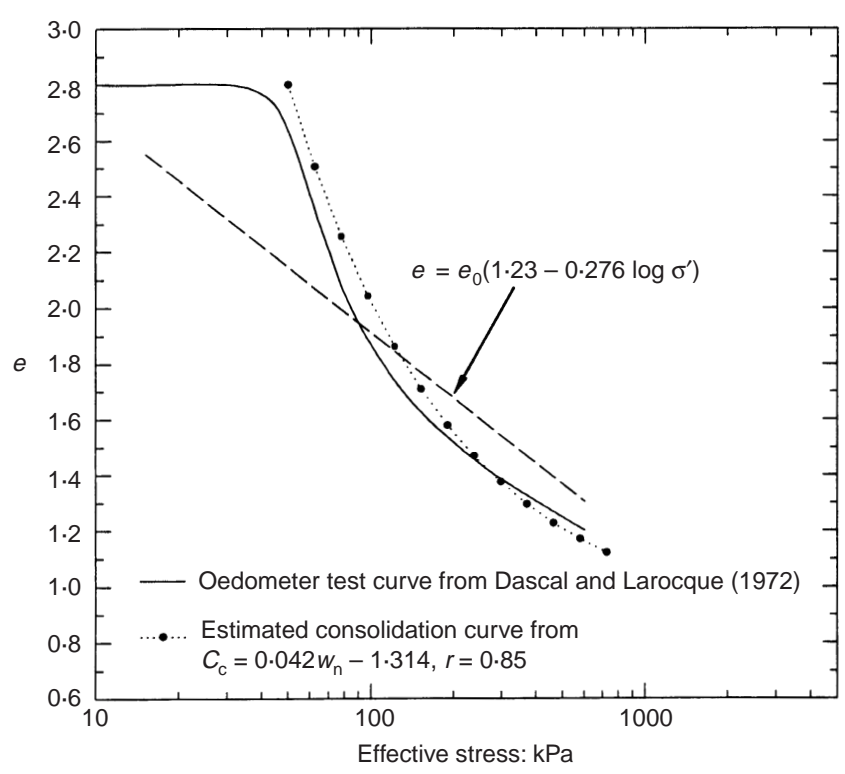

Fig. 12. Plot of example oedometer test curve from Dascal \& Laroque (1973); $C_{\mathrm{c}}-w_{\mathrm{n}}$ relationship derived from linear regression of 23 oedometer tests

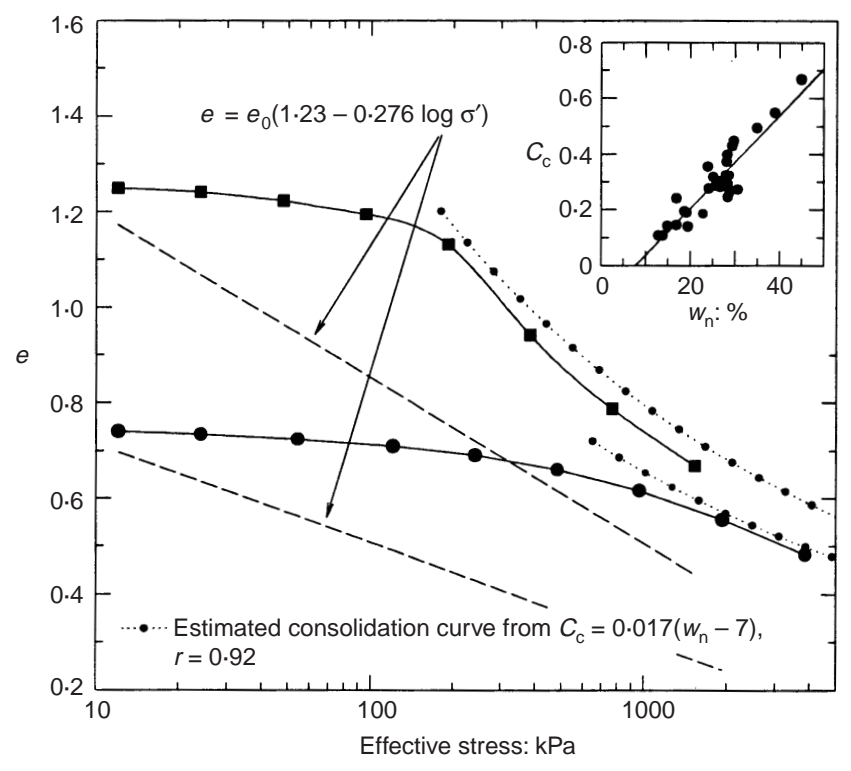

Fig. 13. Plot of $C_{\mathrm{c}}-w_{\mathrm{n}}$ relationship derived from linear regression of multiple oedometer tests (see inset) and example oedometer test curve from Toronto, Ontario

be considered representative of remoulded compression behaviour for all soft cemented soil deposits, as the authors imply. Locally relevant correlations may provide better physical and statistical understandings of compressibility for specific deposits. It is questionable whether the authors' method provides any better insight into the generalized behaviour of cemented soils that cannot be adequately addressed by conventional empirical correlations. Most importantly, the authors have not considered any specific causes of cementation. The data presented in this discussion, chosen at random from publications and consulting work, question the fundamental theoretical principle of a constant 'bond stress' identified by the oedometric yield stress as advocated in the paper.

\section{Author's reply}

The authors appreciate the discussion contribution on the compressibility behaviour of soft clays with possible natural cementation. They welcome the opportunity to provide further information and explanation wherever feasible.

What can be deduced by dividing the in situ void ratio $\left(e_{0}\right)$ by the void ratio at liquid limit water content $\left(e_{\mathrm{L}}\right)$ is the computed intrinsic state, in contrast to physical state mentioned by the discusser. The mineralogy and pore chemistry influence the value of $e_{\mathrm{L}}$, and hence the compression path from this state is devoid of any effects of stress history, time and environment, and therefore forms an intrinsic state line for all normally consolidated uncemented soils. Any deviations from this due to sedimentation rate and cementation and other weathering or leaching effects are reflected in the actual $\left(e_{0} / e_{\mathrm{L}}\right)$ values at its present overburden pertaining to a specific deposit. The value of $e_{0}$ could be the same both corresponding to the undisturbed state and that due to reconstituted and remoulded state both being in equilibrium under different stress levels. As stated by the discussers, the $\left(e_{0} / e_{\mathrm{L}}\right)$ could be in any of the zones shown in Fig. 8 (refers to discussion) but still naturally cemented. The treatment in this Technical Note was mainly with respect to the soft soils whose state is above the intrinsic state line, which has considerable compression potential when the applied stresses are of higher magnitude than the yield stress in compression. In such cases, the compression paths are being analysed on the assumption that the cementation bond strength would remain constant or can increase, since, due to compression of the fabric, the increase in cementation bonds per unit volume can compensate for the disruption of bonds due to shear strains resulting from compression under the $K_{0}$ condition or even impart additional resistance dependent upon the magnitude of compression. The authors concur with the discusser's observation that the pattern as per the postulations made are not applicable, particularly when the clays are overconsolidatedcemented. However, the mode of analysis can be regarded as a means to assess the most probable upper bound compression path for clays falling in zone 1 in the absence of compression test and with the yield stress being computed from the strength data. The authors are not familiar with and have not examined the potential of the method that the discusser pointed out of constructing the compression path beyond the point defined by yield stress and initial void ratio as discussed by Kulhawy \& Mayne (1990).

The authors would like to reiterate that the compression behaviour of a soft soil whose intrinsic state is far higher when compared to its state on the intrinsic state line under the same overburden pressure can be analysed within the framework discussed in the Technical Note. The main purpose of the Technical Note is to analyse the behaviour of clays which exhibit non-particulate and particulate behaviour under different stress levels. The analysis of compression characteristics should be done with the assessment of the compression curve as per the equation (8) relevant to that soil or with respect to the reconstituted compression path experimentally generated. The reasons for the discrepancy observed by the discussers cannot be discerned with the information provided. The authors' views are reinforced by the fact that the compression path of undisturbed clay would lie above the intrinsic curve of that clay by the analysis of virgin compression of structured soils provided by Liu \& Carter (1999). It can be seen that, in about 20 cases, the compression curves have the relative disposition discussed above.

\section{REFERENCES}

Becker, D. E., Crooks, J. H. A., Been, K. \& Jefferies, M. G. (1987). Work as a criterion for determining in situ and yield stresses in clays. Can. Geotech. J. 24 549-564.

Boone, S. J. \& Lutenegger, A. J. (1997). Cementation and carbonates in glacially derived cohesive soils of New York State and southwestern Ontario. Can. Geotech. J. 34, No. 4, 534-550.

Dascal, O. \& Larocque, G. S. (1973). Caracteristiques de compressibilite des argiles du complexe Nottaway-Broadback-Rupert (Baie James). Can. Geotech. J. 10, No. 1, 41-63.

Griffiths, F. J. \& Joshi, R. C. (1988). Identification of cementation in overconsolidated clays. Géotechnique 38, No. 3, 451-452. 
Joshi, R. C., Achari, G. \& Griffiths, F. J. (1995). Closure to Discussion on 'An approximate method for estimating the consolidation behaviour of soft sensitive clays' by R. C. Joshi, G. Achari and F. J. Griffiths. Geotech. Testing J., ASTM 18, No. 3, 386-388.

Kulhawy, F. H. \& Mayne, P. (1990). Manual on estimating soil properties for foundation design, Electric Power Research Institute, Report No. EPRI EL-6800.

Liu, M. D. \& Carter, J. P. (1999). Virgin compression of structured soils. Géotechnique 49, No. 1, 43-57.

Masterson, C. J. (1970). The relationship of fabric and bonding to the strength of a sensitive marine clay. MS thesis, University of Western Ontario.

Nagaraj, T. S. \& Srinivasa-Murthy, B. R. (1983). Rationalization of Skempton's compressibility equation. Géotechnique 33, No. 4, 433-443.
Nagaraj, T. S. \& Srinivasa-Murthy, B. R. (1986). A critical reappraisal of compression index equations. Géotechnique 36, No. 1, 27-32.

Nagaraj, T. S., Srinivasa-Murthy, B. R., Vatsala, A. \& Joshi, R. C. (1990). Analysis of compressibility of sensitive soils. J. Geotech. Engng, ASCE 116, No. 1, 105-118.

Quigley, R. M. (1980). Geology, mineralogy, and geochemistry of Canadian soft soils: a geotechnical perspective. Can. Geotech. J. 17, $261-285$.

Sangrey, D. A. (1972). Naturally cemented sensitive soils. Géotechnique 22, No. 1, 139-152.

Vatsala, A., Nagaraj, T. S. \& Srinivasa-Murthy, B. R. (1995). Discussion on 'An approximate method for estimating the consolidation behaviour of soft sensitive clays' by R. C. Joshi, G. Achari and F. J. Griffiths. Geotech. Testing J., ASTM 18, No. 3, 384-386. 